\title{
Indoleamine 2,3-dioxygenase and inducible nitric oxide synthase mediate immune tolerance induced by CTLA4Ig and anti-CD154 hematopoietic stem cell transplantation in a sensitized mouse model
}

\author{
QI-XIANG YE ${ }^{1,2}$, LV-HONG XU $^{1}$, PEI-JIE SHI ${ }^{1}$, TING XIA $^{1}$ and JIAN-PEI FANG ${ }^{1}$ \\ ${ }^{1}$ Department of Pediatrics, Sun Yat-Sen Memorial Hospital, Sun Yat-Sen University, Guangzhou, Guangdong 510120; \\ ${ }^{2}$ Department of Hematology and Oncology, Guangzhou Women and Children's Medical Center, \\ Guangzhou, Guangdong 510623, P.R. China
}

Received October 9, 2015; Accepted February 2, 2017

DOI: $10.3892 / \mathrm{etm} .2017 .4722$

\begin{abstract}
Cytotoxic T-lymphocyte-associated protein 4 immunoglobulin (CTLA4Ig) and anti-cluster of differentiation 154 (anti-CD154) are able to block B7/CD28 and CD40/CD154 co-stimulatory signals in T cells. Additionally, they promote hematopoietic stem cell transplantation (HSCT) in sensitized recipients and are able to induce immune tolerance and complete hematopoietic reconstitution. Indoleamine 2, 3-dioxygenase (IDO) and nitric oxide (NO) have been implicated in $\mathrm{T}$ cell immune tolerance. The aim of the present report was to study the in vivo tolerogenic mechanisms by which CTLA4Ig and anti-CD154 induce transplantation survival in mice receiving HSCT. BALB/c mice were sensitized via splenocyte transfusion and pretreated with CTLA4Ig plus anti-CD154 on day-7. IDO and inducible nitric oxide synthase (iNOS) inhibitors were applied on days-7 to 0 and the mice were divided into 4 groups $(n=10)$ and injected with IDO every other day. The mice were sacrificed on day 0 , and splenocytes were separated to identify $\mathrm{CD} 11 \mathrm{c}^{+}$antigen-presenting
\end{abstract}

Correspondence to: Dr Jian-Pei Fang, Department of Pediatrics, Sun Yat-Sen Memorial Hospital, Sun Yat-Sen University, 107 Yan Jiang Road West, Guangzhou, Guangdong 510120, P.R. China E-mail: jpfang2005@163.com

Abbreviations: HSC, hematopoietic stem cell transplantation; IDO, indoleamine 2, 3-dioxygenase; NO, nitric oxide; iNOS, inducible nitric oxide synthase; i.p., intraperitoneally; 1-MT, 1-methyl-DL-tryptophan; AG, aminoguanidine; MLR, mixed lymphocyte reaction; APC, antigen-presenting cells; CTLA4Ig, cytotoxic T-lymphocyte-associated protein 4 immunoglobulin; anti-CD154, cluster of differentiation antigen 154

Key words: indoleamine 2, 3-dioxygenase, inducible nitric oxide synthase, immune tolerance, hematopoietic stem cell transplantation, cytotoxic T-lymphocyte-associated protein 4 immunoglobulin, anti-cluster of differentiation 154 cells, which were subsequently assessed for IDO expression and activity. The concentration of NO was tested using a nitrate reductase kit. Following the acceptance of allogeneic HSCT, mice were tested for homing and engraftment, as well as survival rate. Application of the IDO inhibitor increased the concentration of NO, whereas a decrease in NO resulted in increased IDO activity. Immune tolerance was abrogated in the presence of both IDO and iNOS inhibitors, whereas this effect was not observed with either compound alone. CTLA4Ig and anti-CD154 may induce immune tolerance by affecting the activity of IDO and iNOS. This tolerance was abrogated in the presence of both IDO and iNOS inhibitors. A cross-regulatory pathway was observed between the IDO and NO pathways, in which the inhibition of IDO stimulated the iNOS pathway and vice versa.

\section{Introduction}

Investigating the methods that are used to induce immune tolerance and studying the theoretical basis of this phenomenon are key challenges in allogeneic tissue transplantation. The application of cytotoxic $\mathrm{T}$ lymphocyte-associated antigen 4 immunoglobulin (CTLA4Ig) and anti-cluster of differentiation 154 (anti-CD154) is able to induce immune tolerance, promote organ engraftment and prolong graft survival time by blocking B7/CD28 and CD40/CD154 co-stimulatory signals in mice and other animals (1-3).

Indoleamine 2, 3-dioxygenase (IDO) is a heme-containing enzyme. It catalyzes the oxidative chemical degradation of the indole ring of tryptophan via the kynurenine metabolism pathway in nonhepatic tissues (4). Previous research has found that the decomposition of tryptophan and its metabolites inhibits $\mathrm{T}$ cell activation and generates cytotoxicity, and it may even induce active $\mathrm{T}$ cell apoptosis $(5,6)$. IDO-induced $\mathrm{T}$ cell tolerance has been demonstrated in in vitro experiments and animal models of transplantation (7). The high expression level of IDO reduces the rate of graft rejection (8).

Nitric oxide (NO) is able to inhibit the activity of IDO, and similarly, the decomposition of tryptophan inhibits the 
interferon (IFN)- $\gamma$-induced expression of inducible nitric oxide synthase (iNOS), indirectly inhibiting the generation of NO (9). Enhanced secretion of NO from activated macrophages may suppress anti-tumor T-cell responses, for instance via the inhibition of T-cell proliferative responses, suppressed production of certain cytokines, induction of T-cell apoptosis and suppression of cytolytic responses (10). Thus, IDO and NO are responsible for the impaired capacity of allograft rejection to stimulate allogeneic $\mathrm{T}$ cells.

IDO and iNOS have previously been reported as potent immunosuppressive enzymes. Potula et al (11) demonstrated that the manipulation of immunosuppressive IDO activity (application of 1-methyl-DL-tryptophan) in HIV may enhance the generation of human immunodeficiency virus (HIV)-1-specific CTLs, leading to the elimination of HIV-1-infected macrophages in the brain. Badn et al (12) demonstrated that the inhibition of iNOS enhances IFN- $\gamma$-based immunotherapy in experimental intracerebral tumors, implying that NO released post-immunization has mainly immunosuppressive effects. Hill et al (13) reported that the administration of IDO and iNOS inhibitors led to acute rejection of heart allografts in rats. However, the indefinite graft survival observed with CTLA4Ig did not have an effect in the presence of either inhibitor alone. The same result was obtained in a CTLA4Ig-based model of bone marrow transplantation (4).

In the present study, it was examined whether the IDO and iNOS pathways participate in the immune tolerance induced by CTLA4Ig and anti-CD154 in hematopoietic stem cell transplantation (HSCT), as well as the underlying tolerogenic mechanisms.

\section{Materials and methods}

Ethics statement. The present study was approved by Sun-Yat Sen University. All of the human studies were performed in accordance with the ethical standards established in the 1964 Declaration of Helsinki and its later amendments. All of the patients provided written informed consent prior to their inclusion in the study.

Animals. A total of 40 male BALB/c (H-2Db) and 40 C57BL/6 (H-2Dd) mice, aged 6-8 weeks and weighing 18-20 g, were purchased from the Experimental Animal Center of Sun-Yat Sen University (Guangzhou, China). All of the mice were maintained under pathogen-free conditions. Animals were housed at a temperature of $22-28^{\circ} \mathrm{C}$ and $45-50 \%$ humidity with a 12-h light/dark cycle, provided with autoclaved food and water ad libitum.

Sensitized model establishment and pretreatment. BALB/c mice were sensitized via the transfusion of allogeneic splenocytes from C57BL/6 mice that were separated by erythrocyte lysis (blood sample taken via the tail vein) on day-7. Cellular activity was found to be $>99 \%$ via trypan blue staining and a total of $1 \times 10^{6}$ splenocytes were subsequently injected via the tail vein into $\mathrm{BALB} / \mathrm{c}$ mice to establish the sensitized model. These mice were treated with IDO and iNOS inhibitors, respectively, on days -7 to 0 following intravenous injection with CTLA4Ig (Abcam, Cambridge, MA, USA) and
anti-CD154 (500 $\mu \mathrm{g} /$ mouse, ab2391; eBioscience; Thermo Fisher Scientific, Inc., Waltham, MA, USA) on day -7.

The mice were divided into 4 groups. In the first group, each mouse was injected with $10 \mathrm{mg}$ 1-methyl-DL-tryptophan (1-MT; Sigma-Aldrich; Merck KGaA, Darmstadt, Germany) i.p. The second group received $50 \mathrm{mg} / \mathrm{kg} \mathrm{AG}$ (Sigma Aldrich; Merck KGaA) i.p., and the third group was treated with 1-MT+AG (as described above). The fourth group served as a negative control and these mice were injected with an equal volume of PBS. There were 10 mice in each group, and the injections were performed every other day (Fig. 1).


According to the use of Ficoll gradients, a single spleen cell suspension was obtained following the separation of mouse spleen cells and lysis using red blood cell lysis buffer (Sigma-Aldrich; Merck KGaA) (14). This suspension was centrifuged at $200 \mathrm{x} \mathrm{g}$ for $10 \mathrm{~min}$ at $37^{\circ} \mathrm{C}$, then resuspended in $400 \mu \mathrm{l}$ of PBS ( $8.0 \mathrm{~g}$ of sodium phosphate and $0.2 \mathrm{~g}$ of sodium chloride per liter, $\mathrm{pH}$ 7.2) and $100 \mu \mathrm{l}$ of CD11c MicroBeads (Miltenyi Biotec GmbH, Bergisch Gladbach, Germany), mixed, and incubated at $4^{\circ} \mathrm{C}$ for $15 \mathrm{~min}$. A total of $1.5 \mathrm{ml}$ of buffer was subsequently added to this mixture, centrifuged at $200 \mathrm{x} \mathrm{g}$ for $10 \mathrm{~min}$ at $4^{\circ} \mathrm{C}$, and then resuspended in $500 \mu \mathrm{l}$ buffer. The separation column was fixed on a MACS separator (Miltenyi Biotec $\mathrm{GmbH}$ ), and the cell suspension was poured into the separation column. A total of $500 \mu 1$ of buffer was added to the column, and after the buffer had passed completely through, additional buffer was added. This process was repeated 3 times, and then the separation column was removed from the MACS separator and placed in a centrifuge tube. A total of $1 \mathrm{ml}$ buffer was added to the column and was then extruded using a piston extruder. The CD11 $\mathrm{c}^{+}$cell suspension was then collected and resuspended in RPMI-1640 medium (Gibco; Thermo Fisher Scientific, Inc.). Cells $\left(10^{6}\right.$ cells $\left./ \mu \mathrm{g}\right)$ were labeled with mouse anti-CD11 $\mathrm{c}^{+}$monoclonal antibodies (cat no. 48-0116-41; eBioscience; Thermo Fisher Scientific, Inc.) (identifying different epitopes compared with the antibodies labeling the magnetic beads) conjugated with phycoerythrin at $4^{\circ} \mathrm{C}$ for $30 \mathrm{~min}$ and assessed by FACSCalibur flow cytometry (BD Biosciences, San Jose, CA, USA). The cells were stained with $0.4 \%$ trypan blue at room temperature for $10 \mathrm{~min}$. Cell viability was detected immediately after staining.

Detection of IDO expression level by western blot analysis. The sorted cells, described above, were added to precooled radioimmunoprecipitation assay buffer (Sigma-Aldrich; Merck $\mathrm{KGaA}$ ) in an ice bath and the homogenate was centrifuged at $10,000 \mathrm{x} \mathrm{g}$ at $4^{\circ} \mathrm{C}$ for $10 \mathrm{~min}$. The supernatant was collected, and protein quantification was performed according to the Bradford method (15). Equal amounts of protein (20 $\mu \mathrm{g}$ protein in each lane) were separated by SDS-PAGE and transferred to a nitrocellulose membrane, the membrane was washed twice with PBS containing $0.1 \%$ Tween-20 buffer and then incubated with blocking buffer (Thermo Fisher Scientific, Inc.) overnight at room temperature. The membrane was subsequently incubated with IDO antibody (1:400; ab106134; EMD Millipore, Billerica, MA, USA) overnight at $4^{\circ} \mathrm{C}$ and washed 3 times with TBST for $10 \mathrm{~min}$. The horseradish peroxidase-labeled secondary antibody (cat no. ab131336; Abcam) was diluted in 


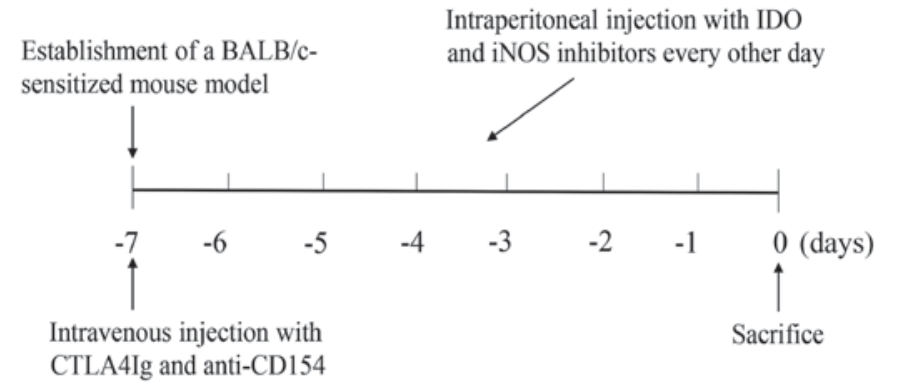

Figure 1. Experimental protocol of sensitized model establishment and pretreatment prior to sacrifice. CTLA4Ig, cytotoxic T-lymphocyte-associated protein 4 immunoglobulin; CD154, cluster of differentiation 154; IDO, indoleamine; iNOS, inducible nitric oxide synthase.

PBS and $0.05 \%$ Tween-20 to $1: 4,000$ and the membrane was incubated with this for $2 \mathrm{~h}$ at room temperature. The membrane was subsequently washed 3 times with TBST for 10 min each. The experiments were repeated three times. Western blots were quantified by measuring the relative density of protein bands using ImageJ software (National Institutes of Health, Bethesda, MD, USA).

Chemiluminescence, image development and fixation. The reagents contained in an enhanced chemiluminescence kit (GE Healthcare, Chicago, IL, USA) were mixed and added to the surface of the polyvinylidene difluoride membrane (EMD Millipore). The membrane was incubated for approximately $3 \mathrm{~min}$ at $4^{\circ} \mathrm{C}$, and the film was developed in the dark. Different exposure times were chosen according to the intensity of the light. The film was placed in developing solution (Sigma-Aldrich; Merck KGaA), and was immediately placed into a fixing bath (Thermo Fisher Scientific, Inc.) when the bands appeared. ImageJ software (National Institutes of Health) was used to analyze the intensity of the target protein bands.

Detection of IDO activity by HPLC-UV (15). The chromatographic column used was a symmetry shields RP-C18 column (150x3.9 mm; internal diameter, $5 \mu \mathrm{m}$; Waters Corporation, Milford, MA, USA) and the mobile phase was $15 \mathrm{mM}$ acetic acid-sodium acetate (containing 2.7\% acetonitrile, $\mathrm{pH} 3.6$; Beijing Chemical Reagent Factory, Beijing, China). The flow rate was $1.0 \mathrm{ml} / \mathrm{min}$, and the UV detection wavelength was $225 \mathrm{~nm}$ measured at room temperature. The rats of all groups were sacrificed by intraperitoneal injection of overdoses of sodium pentobarbital (300 mg/kg; Sigma-Aldrich; Merck $\mathrm{KGaA}$ ) and then both eyeballs and blood were harvested. These were placed in clean coagulant tubes, and the blood was centrifuged within $30 \mathrm{~min}$ at $3,000 \mathrm{x}$ g for $10 \mathrm{~min}$ at $4^{\circ} \mathrm{C}$ to obtain the serum. The serum was placed in $0.5-\mathrm{ml} \mathrm{EP}$ tubes, mixed completely, and preserved at $-20^{\circ} \mathrm{C}$. The serum was brought to room temperature and $200 \mu \mathrm{l}$ of each serum sample was placed in an Eppendorf tube, followed by the addition of $5 \%$ perchloric acid solution (v/v; Beijing Chemical Reagent Factory) in a vortex mixer for $30 \mathrm{sec}$, and incubation at room temperature for $10-15$ min to completely precipitate the serum protein. The sample was then centrifuged for $5 \mathrm{~min}$ at $10,000 \mathrm{x} g$ at room temperature, and $20 \mu \mathrm{l}$ of the supernatant was used for analysis. Kyn and Trp had peak retention values in the comparison and superposition methods used for the qualitative analysis, and external standard methods were used to determine the peak area for quantitative analysis. Data processing was completed using a PC800 chromatography workstation (Waters Corporation). The Kyn concentration in the sera $(\mu \mathrm{mol} / \mathrm{l})=($ peak area of serous Kyn/peak area of standard liquid) $x$ Kyn concentration of the standard liquid x 2 .

Detection of NO concentration. The cell supernatants from cultured BALB/c spleen cells stimulated with C57BL/6 mouse spleen cells were collected and assessed using an NO kit (Beyotime Institute of Biotechnology, Shanghai, China).

Mixed lymphocyte reaction (MLR). The mouse spleen lymphocytes were separated using the Ficoll method (16). The spleen was separated aseptically, rinsed repeatedly using ice-cold PBS (30 ml/wash) with a syringe, resuspended in $3 \mathrm{ml}$ of PBS and slowly added to $3 \mathrm{ml}$ of mouse lymphocytes in the upper separation medium. The samples were then incubated for $20 \mathrm{~min}$ at room temperature. The samples were centrifuged for $10 \mathrm{~min}$ at $2,000 \mathrm{x} \mathrm{g}$, and the white rete in middle layer was collected, rinsed twice with PBS, and resuspended in RPMI-1640 complete culture solution. C57BL/6 lymphocytes were used to stimulate the cells, and normal BALB/c lymphocytes were used in the sensitization model as responder cells. The stimulated cells were treated with mitomycin C (25 $\mu \mathrm{g} / \mathrm{ml}$; Kyowa Hakko Kogyo Bio Co., Ltd., Tokyo, Japan), incubated at $37^{\circ} \mathrm{C}$ for $30 \mathrm{~min}$, and rinsed 3 times with nutrient solution (RPMI-1640) The cell suspension $\left(1 \times 10^{6}\right.$ cells $\left./ \mathrm{ml}\right)$ was prepared in RPMI-1640 nutrient solution, and $100 \mu \mathrm{l}$ of this suspension was placed in each well of a 96-well culture plate. The responder cells were then added at a concentration of $1 \times 10^{5}$ cells in $100 \mu \mathrm{l} / \mathrm{well}$. The stimulating and responding cells were also placed in separate wells for analysis (resulting in 3 wells) and cultivated at $37^{\circ} \mathrm{C}$ in a $\mathrm{CO}_{2}(5 \%)$ incubator for 5 days. BrdU (EMD Millipore) was added to the cells, followed by an additional incubation at $37^{\circ} \mathrm{C}$ for $16 \mathrm{~h}$. Stop buffer (Gibco; Thermo Fisher Scientific, Inc.) was added, and then the optical density of each well was tested using an ultraviolet spectrophotometer at a wavelength of $450 / 550 \mathrm{~nm}$.

Allogeneic HSCT. All of the groups in the sensitization model were pretreated on day 0 using lethal dose linear accelerator irradiation. After 4-6 h, they received $1 \times 10^{7} \mathrm{C} 57 \mathrm{BL} / 6$ bone marrow cells, which were transplanted intravenously via tail injection. The survival of the mice was then monitored. Mouse bone marrow cells were fluorescein isothiocyanate-labeled with rat anti-mouse $\mathrm{H}-2 \mathrm{D}^{\mathrm{b}}$ antibody (cat no. MBS520317; MyBioSource, San Diego, CA, USA) and examined by flow cytometry every week (BD Biosciences). The chimerism of the bone marrow cells was represented by the rate of $\mathrm{H}-2 \mathrm{D}^{\mathrm{b}}$ positive cells.

Statistical analysis. All data are expressed as the mean \pm standard error of the mean. Data were analyzed using SPSS v. 19.0 (IBM SPSS, Armonk, NY, USA). Comparisons between experimental results were conducted using one-way analysis of variance. Log-rank test p-values were determined using the 



Figure 2. Expression of IDO protein in APCs in the 4 groups treated with the indicated co-stimulatory signal blockers. GAPDH served as an internal quantitative control. The data are representative of 3 independent experiments and expressed as means \pm standard deviation. IDO, indoleamine; APC antigen-presenting cell; 1-MT, 1-methy-DL-tryptophan; AG, aminoguanidine.

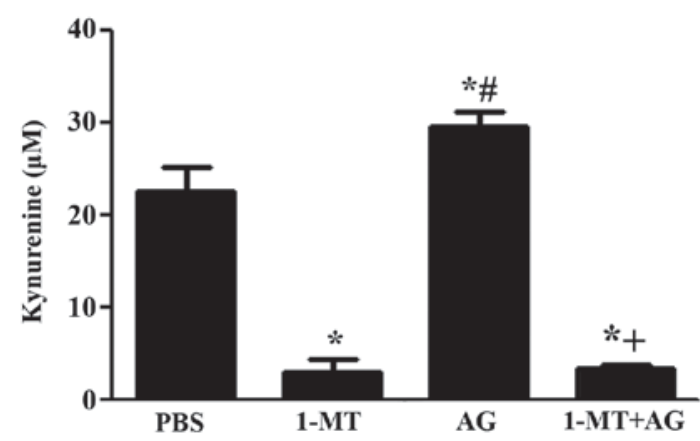

Figure 3. Kynurenine concentration in the different groups. The data are representative of 3 independent experiments and expressed as means \pm standard deviation. ${ }^{*} \mathrm{P}<0.01$ vs. $\mathrm{PBS},{ }^{\prime} \mathrm{P}<0.01$ vs. $1-\mathrm{MT},{ }^{+} \mathrm{P}<0.01$ vs. AG. $1-\mathrm{MT}$, 1-methyl-DL-tryptophan; AG, aminoguanidine.



Figure 4. NO concentration in the different groups. The data are representative of 3 independent experiments and expressed as means \pm standard deviation. ${ }^{*} \mathrm{P}<0.01$ vs. $\mathrm{PBS},{ }^{\text {"P }} \mathrm{P}<0.01$ vs. $1-\mathrm{MT},{ }^{+} \mathrm{P}<0.01$ vs. AG. NO, nitric oxide; 1-MT, 1-methy-DL-tryptophan; AG, aminoguanidine.

Kaplan-Meier method to compare survival curves. $\mathrm{P}<0.05$ was considered to indicate a statistically significant difference.

\section{Results}

IDO protein expression level. There were no significant differences in IDO protein levels in APCs between the

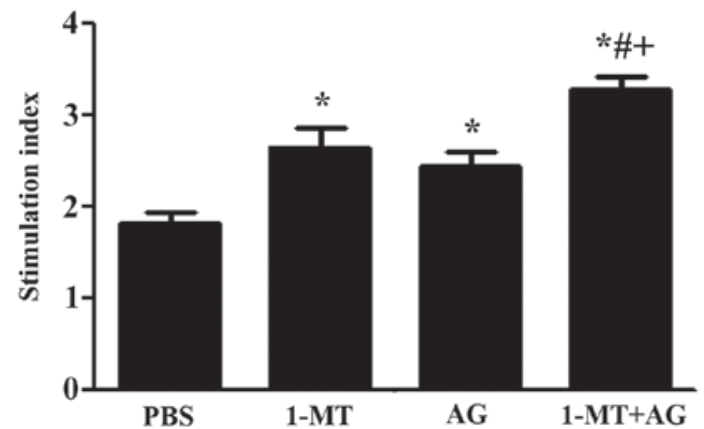

Figure 5. Stimulatory index results for the MLR in each group. The data are representative of 3 independent experiments and expressed as means \pm standard deviation. ${ }^{*} \mathrm{P}<0.01$ vs. $\mathrm{PBS},{ }^{\#} \mathrm{P}<0.01$ vs. $1-\mathrm{MT},{ }^{+} \mathrm{P}<0.01$ vs. AG. MLR, mixed lymphocyte reaction; 1-MT, 1-methy-DL-tryptophan; AG, aminoguanidine.

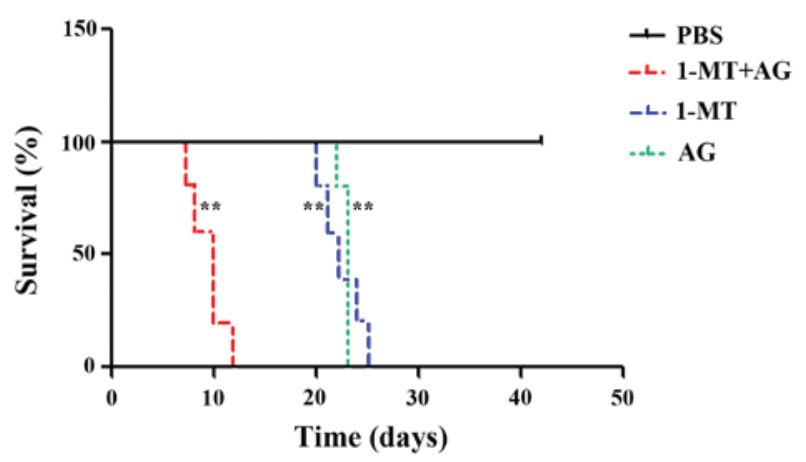

Figure 6. Survival cures for the recipients under irradiation post-transplantation. ${ }^{* *} \mathrm{P}<0.001$ vs. PBS. 1-MT, 1-methy-DL-tryptophan; AG, aminoguanidine.

4 groups (Fig. 2). This indicates that neither IDO nor NOS inhibitors were able to affect IDO protein expression in APCs in which co-stimulatory signals are blocked.

Activity of IDO. The levels of kynurenine and tryptophan were determined via HPLC to assess the activity of IDO. The levels of Kyn in the 1-MT group and 1-MT+AG group were significantly decreased compared with the AG and PBS groups $(\mathrm{P}<0.01$; Fig. 3). The Kyn level in the AG group was significantly increased compared with the PBS group $(\mathrm{P}<0.01)$.

Concentration of NO. The concentrations of $\mathrm{NO}$ in the $\mathrm{AG}$ and $1-\mathrm{MT}+\mathrm{AG}$ groups were significantly decreased compared with those in the 1-MT and PBS groups ( $\mathrm{P}<0.01$; Fig. 4). NO levels were significantly increased in the 1-MT group compared with the PBS group $(\mathrm{P}<0.01)$.

$M L R$. The MLR demonstrated that the stimulatory index for the 1-MT+AG group was increased significantly compared with the PBS, AG and 1-MT groups $(\mathrm{P}<0.01)$. The stimulation indexes for the AG and 1-MT groups were significantly increased compared with the PBS group ( $\mathrm{P}<0.01 ;$ Fig. 5).

Survival assessment and chimera analysis. All mice in the PBS group were alive at 42 days post-transplantation, whereas the mice in the 1-MT+AG group all died between 7 and 12 days post-transplantation (Fig. 6). The log-rank analysis 

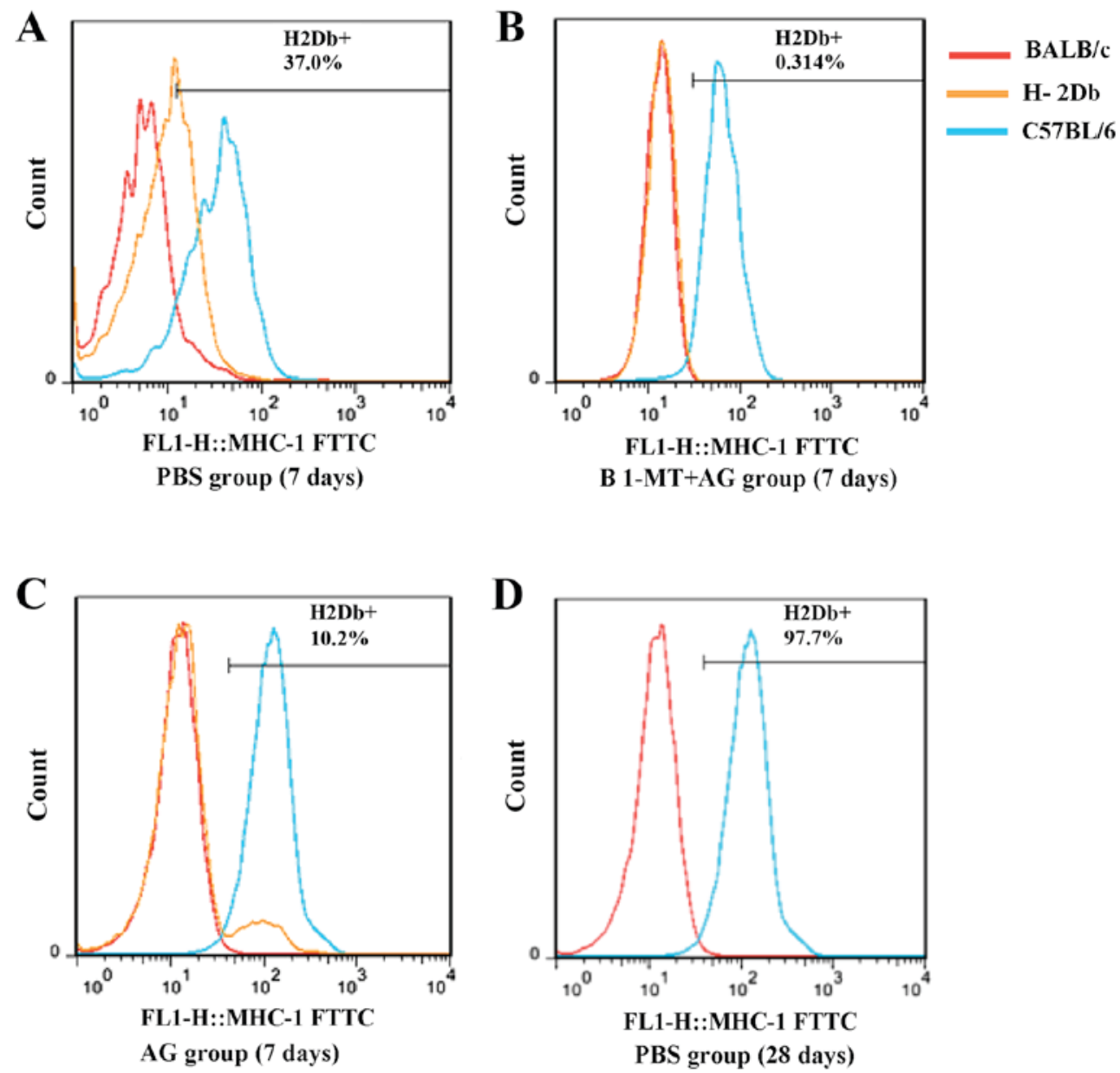

Figure 7. Percentage of $\mathrm{H}-2 \mathrm{D}^{\mathrm{b}+}$ positive cells in the bone marrow of recipients post-transplantation. (A) PBS group (7 days). (B) 1-MT+AG group (7 days). (C) AG group (7 days). (D) PBS group (28 days). MHC, major histocompatibility complex; FITC, fluorescein isothiocyanate; 1-MT, 1-methy-DL-tryptophan; AG, aminoguanidine.

revealed that there were statistically significant differences between these 2 groups $(\mathrm{P}<0.001)$. The median survival times for the AG and 1-MT groups were 23 and 22 days, respectively, significantly lower compared with the PBS group $(\mathrm{P}<0.001)$. However, no significant differences were observed between the AG and 1-MT groups. Specific weight loss and the presence of a significant decrease in activity, poor mental capabilities signs were used as humane endpoints for mice, however, there were no symptoms of graft vs. host disease (GVHD), e.g. significant loss of hair, erythra or diarrhea.

At day 7 post-transplantation, chimera analysis (Fig. 7) revealed that the percentage of $\mathrm{H}-2 \mathrm{D}^{\mathrm{b}+}$ cells in the mouse bone marrow from the PBS and 1-MT+AG groups were 40.2 \pm 3.63 and $0.36 \pm 0.12 \%$, respectively, and the difference between these 2 groups was statistically significant $(\mathrm{P}<0.001 ;$ Fig. 7$)$. The AG and 1-MT groups were found to have values of $12.4 \pm 2.13$ and $11.8 \pm 3.12 \%$, respectively, with no significant difference. At day 28 post-transplantation, the percentage of $\mathrm{H}-2 \mathrm{D}^{\mathrm{b}+}$ cells in the recipients in the PBS group was $>90 \%$.

\section{Discussion}

IDO is an enzyme that serves a role in tryptophan catabolism via the kynurenine pathway. It contains ferroprotoporphyrin and is able to catalyze the modification of tryptophan by oxi-cracking its indole ring (8). Previous studies have reported that the decomposition and metabolic products of tryptophan are able to inhibit $\mathrm{T}$ cell activation, generate cytotoxicity and even induce the apoptosis of activated $\mathrm{T}$ cells $(5,6)$. Studies have demonstrated that IDO has a role in the induction of immune tolerance in pregnancy, transplantation, autoimmune disease and tumors (17-20). Under physiological conditions, the antigenic cell surface expression of IDO is necessary for fetal immune tolerance, oral antigen-induced immune tolerance and the inhibition of adverse autoimmunity reactions $(21,22)$. Sucher et al (23) also found that major histone complex-mismatched implants may result in acute rejection reactions in IDO gene knockout mice, whereas wild mice with a high rate of tryptophan decomposition are able to survive for a long time, indicating that IDO serves a critical role in the induction of immune tolerance in the implant.

In experimental animal models, CTLA4-Ig is used to induce immune tolerance in the implant by competitively blocking the CD28 co-stimulatory molecule pathway $(24,25)$. It functions as an inverse signal to stimulate the dendritic cell (DC) -induced IFN- $\gamma$-dependent tryptophan decomposition pathway. Research has revealed that soluble CTLA4-iIg treatment in diabetic mice following allogeneic islet cell 
transplantation may extend the implant survival time, and this effect is blocked by the IDO enzyme inhibitor 1-MT (7). Orabona et al (26) confirmed that CTLA4-Ig functions by binding to its ligand, B7, to induce splenic CD11c ${ }^{+}$DCs to secrete IFN- $\gamma$ and then facilitate the expression of IDO. In addition, it is able to reduce and even block the proliferation of $\mathrm{T}$ lymphocytes via the tryptophan decomposition pathway (26).

In the present study, it was demonstrated that, following the application of CTLA4-Ig and anti-CD154 to block co-stimulatory signaling, IDO protein expression was not affected by additional applications of the IDO inhibitor, iNOS inhibitor or both inhibitors together; however, its activity was remarkably decreased by $1-\mathrm{MT}$. These results demonstrate that the expression IDO protein is not related to its activity. In in vivo investigations of monocytes, López et al (27) also found reduced activity of IDO protein with increases in IDO protein expression.

NO is an important second messenger in cells, a novel type of neural transmitter that is involved in normal physiological processes and is biosynthesized endogenously from L-arginine following catalysis by NOS (28). NO is an active free radical that is widespread in various cell types and serves extensive roles in the immune response (27). NOS mediates the synthesis of NO and is present in many tissues of the organism (29). To date, 3 isozymes have been described: Neuronal NOS (nNOS), endothelial NOS (eNOS), and iNOS. The first 2 types are also collectively known as 'constitutive NOS'. nNOS and eNOS are predominantly expressed in neurocytes and endotheliocytes, respectively (30). They are calcium ion-dependent enzymes and exhibit low levels of NO generation (31). In addition, iNOS functions independently of calcium ions and may be induced by cell factors or other substances to generate a large quantity of NO until degradation (32).

Previous research has revealed that NO is able to prolong the survival time of implants and mitigate GVHD following bone marrow transplantation $(33,34)$. In the present study, a remarkable decrease in the concentration of $\mathrm{NO}$ was observed following AG application, which indicates that AG may effectively inhibit iNOS activity.

The MLR results demonstrated that the stimulation index significantly increased in the 1-MT+AG group compared with the PBS, AG and MT-1 groups. This indicates that blockade of the co-stimulatory pathways may induce the activation of immune reactions in allogeneic spleen cells.

The stimulation indexes in both the AG and 1-MT groups were significantly increased compared with the PBS group, indicating that the application of IDO enzyme inhibitor or iNOS inhibitor alone may also activate immune reactions to allogeneic spleen cells to some extent in recipients. Subsequent observation of survival in various groups found that mice in the PBS group were able to survive for a long time, whereas the mice in the 1-MT+AG group died within 7-12 days. The mosaic analysis demonstrated that the allogeneic HSCs couldn't undergo implantation. In contrast, mosaic analysis of the PBS group demonstrated that the allogeneic HSCs were sufficient to complete hematopoietic reconstitution. However, mice with ineffective HSC implantation within 7 days in the AG or 1-MT group ( $10 \%$ in each group) succumbed to this as a consequence of the exhaustion of hematopoiesis.
These results suggest that the induction of immune tolerance by CTLA4Ig and anti-CD154 to block co-stimulatory pathways is related to IDO and iNOS. In the present study, the induction of immune tolerance was blocked by applying inhibitors, and the combined application of IDO and iNOS inhibitors had a greater suppressive effect compared with either inhibitor alone on the abrogation of immune tolerance.

However, the results reported by Hill et al (13) demonstrated that CTLA4Ig was able to induce the long-term survival of heart transplant allografts, whereas the application of AG or 1-MT did not abrogate the immune tolerance, and simultaneous application of AG or 1-MT resulted in an acute rejection response. The discrepancies between the outcome of the present study and these previous findings may be due to the selection of a sensitized model and the use of an inhibitor.

In agreement with the study results reported by Hill et al (13), in the present study it was demonstrated that the activity of NO and IDO increased in the 1-MT and AG groups compared with the PBS group. This indicates the presence of cross-complementary functions between the IDO and NO enzymes in the induction of immune tolerance via blocking the co-stimulatory signaling pathways. Therefore, when IDO enzyme activity is inhibited, the activity of the NO enzyme will increase and vice versa.

Previous studies have reported that NO is able to inhibit the activity of IDO by reacting with the heme iron situated in its active site (34-36). NO inhibits IDO at the transcriptional level and accelerates the decomposition of IDO protein, thereby affecting its stability (37). The underlying mechanism includes the direct modification of IDO protein through nitration, or indirect regulation via the nitrosylation of amino acid residues to replace or modify other transcription factors, regulating IDO enzyme activity and stability in the entire cell microenvironment $(17,38)$.

The combination of the nitration of peroxidized nitro groups due to the NO enzyme and 3 key tyrosine residues in the IDO enzyme can cause its deactivation. The IDO enzyme also inhibits the generation of NO (39). Catabolites of tryptophan, such as 3-hydroxyl ammonia, inhibit IFN- $\gamma$-induced iNOS

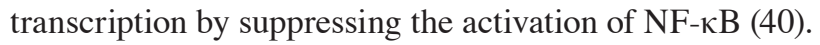

The exhaustion of tryptophan may similarly inhibit IFN- $\gamma$-induced iNOS transcription (41). Although the expressions of IDO and NO, as well as their mutual regulations, vary in different tissues and cells $(26,35,42,43)$, previous studies have reported that regulation of T-cell reactions by NO and tryptophan does not occur via the redundant alternative pathway, and the mutual regulation between the 2 enzymes favors the induction of immune tolerance in the implant $(13,44)$.

In summary, as a treatment for sensitized recipients, CTLA4-Ig and anti-CD145 are able to induce immune tolerance and facilitate allogeneic HSC implantation. The underlying mechanism may be related to their influence on the activity of IDO and NO. Induced immune tolerance is abrogated via the simultaneous application of IDO and iNOS inhibitors. A cross-complementary function was observed between the IDO and NO enzymes, indicating that when the activity of the IDO enzyme is inhibited, NO enzyme activity will increase and vice versa.

The induction of immune tolerance by blocking co-stimulatory signaling may be achieved through the regulation of 
IDO and NO activity, which may represent a novel treatment target following the clinical application of CTLA4Ig and anti-CD154.

\section{Acknowledgements}

This work was supported in part by the Guangdong Province Science and Technology Program for Social Development project (grant no. 2012B0318-00074) and the National Natural Science Foundation of China (grant no. 81370603). The authors would like to thank the Center for Stem Cell Biology and Tissue Engineering and the Animal Center at Sun Yat-Sen University for technical assistance.

\section{References}

1. Larsen CP, Elwood ET, Alexander DZ, Ritchie SC, Hendrix R, Tucker-Burden C, Cho HR, Aruffo A, Hollenbaugh D, Linsley PS, et al: Long-term acceptance of skin and cardiac allografts after blocking CD40 and CD28 pathways. Nature 381: 434-438, 1996

2. Nabeyama K, Yasunami Y, Toyofuku A, Nakano M, Satoh M, Matsuoka N, Ono J, Kamada M, Uede T, Todo S and Ikeda S: Beneficial effects of costimulatory blockade with anti-inducible costimulator antibody in conjunction with CTLA4Ig on prevention of islet xenograft rejection from rat to mouse. Transplantation 78: 1590-1596, 2004.

3. Tung TH, Mackinnon SE and Mohanakumar T: Costimulation blockade of CD40 and CD28 pathways in limb transplantation. Transplant Proc 40: 3723-3724, 2008.

4. Pree I, Bigenzahn S, Fuchs D, Koporc Z, Nierlich P, Winkler C, Brandacher G, Sykes M, Muehlbacher F, Langer F and Wekerle T: CTLA4Ig promotes the induction of hematopoietic chimerism and tolerance independently of indoleamine-2,3-dioxygenase. Transplantation 83: 663-667, 2007.

5. Munn DH, Sharma MD, Baban B, Harding HP, Zhang Y, Ron D and Mellor AL: GCN2 kinase in T cells mediates proliferative arrest and anergy induction in response to indoleamine 2,3-dioxygenase. Immunity 22: 633-642, 2005.

6. Fallarino F, Grohmann U, Vacca C, Bianchi R, Orabona C, Spreca A, Fioretti MC and Puccetti P: T cell apoptosis by tryptophan catabolism. Cell Death Differ 9: 1069-1077, 2002.

7. Grohmann U, Orabona C, Fallarino F, Vacca C, Calcinaro F, Falorni A, Candeloro P, Belladonna ML, Bianchi R, Fioretti MC and Puccetti P: CTLA-4 ndash Ig regulates tryptophan catabolism in vivo. Nat Immunol 3: 1097-1101, 2002.

8. Mulley WR, Li YQ, Wee JL, Dodge N, Christiansen D, Simeonovic C, Ierino FL and Sandrin MS: Local expression of IDO, either alone or in combination with CD40Ig, IL10 or CTLA4Ig, inhibits indirect xenorejection responses. Xenotransplantation 15: 174-183, 2008.

9. Bauer H, Jung T, Tsikas D, Stichtenoth DO, Frölich JC and Neumann C: Nitric oxide inhibits the secretion of T-helper 1and T-helper 2-associated cytokines in activated human T cells. Immunology 90: 205-211, 1997.

10. Medot-Pirenne M, Heilman MJ, Saxena M, McDermott PE and Mills CD: Augmentation of an antitumor CTL response in vivo by inhibition of suppressor macrophage nitric oxide. J Immunol 163: 5877-5882, 1999.

11. Potula R, Poluektova L, Knipe B, Chrastil J, Heilman D, Dou H, Takikawa O, Munn DH, Gendelman HE and Persidsky Y: Inhibition of indoleamine 2,3-dioxygenase (IDO) enhances elimination of virus-infected macrophages in an animal mode of HIV-1 encephalitis. Blood 106: 2382-2390, 2005.

12. Badn W, Hegardt P, Fellert MA, Darabi A, Esbjörnsson M, Smith KE, Janelidze S, Salford LG, Visse E and Siesjö P: Inhibition of inducible nitric oxide synthase enhances anti-tumour immune responses in rats immunized with IFN-gamma-secreting glioma cells. Scand J Immunol 65 : 289-297, 2007

13. Hill M, Zagani R, Voisine C, Usal C and Anegon I: Nitric oxide and indoleamine 2,3-dioxygenase mediate CTLA4Ig-induced survival in heart allografts in rats. Transplantation 84: 1060-1063, 2007.
14. Pignol B, Hénane S, Sorlin B, Rola-Pleszczynski M, Mencia-Huerta JM and Braquet P: Effect of long-term treatment with platelet-activating factor on IL-1 and IL-2 production by rat spleen cells. J Immunol 145: 980-984, 1990.

15. Kruger NJ: The Bradford method for protein quantitation. Methods Mol Biol 32: 9-15, 1994.

16. Ho CY, Lau CB, Kim CF, Leung KN, Fung KP, Tse TF, Chan HH and Chow MS: Differential effect of Coriolus versicolor (Yunzhi) extract on cytokine production by murine lymphocytes in vitro. Int Immunopharmacol 4: 1549-1557, 2004.

17. Mellor AL and Munn DH: IDO expression by dendritic cells: Tolerance and tryptophan catabolism. Nat Rev Immunol 4: 762-774, 2004.

18. Uyttenhove C, Pilotte L, Théate I, Stroobant V, Colau D, Parmentier N, Boon T and Van den Eynde BJ: Evidence for a tumoral immune resistance mechanism based on tryptophan degradation by indoleamine 2,3-dioxygenase 9: 1269-1274, 2003.

19. Curti A, Aluigi M, Pandolfi S, Ferri E, Isidori A, Salvestrini V, Durelli I, Horenstein AL, Fiore F, Massaia M, et al: Acute myeloid leukemia cells constitutively express the immunoregulatory enzyme indoleamine 2,3-dioxygenase. Leukemia 21: 353-355, 2007.

20. Munn DH: Indoleamine 2,3-dioxygenase, tumor-induced tolerance and counter-regulation. Curr Opin Immunol 18: 220-225, 2006.

21. Munn DH, Zhou M, Attwood JT, Bondarev I, Conway SJ, Marshall B, Brown C and Mellor AL: Prevention of allogeneic fetal rejection by tryptophan catabolism. Science 281: 1191-1193, 1998.

22. Zhu BT: Development of selective immune tolerance towards the allogeneic fetus during pregnancy: Role of tryptophan catabolites (Review). Int J Mol Med 25: 831-835, 2010.

23. Sucher R, Fischler K, Oberhuber R, Kronberger I, Margreiter C, Ollinger R, Schneeberger S, Fuchs D, Werner ER, Watschinger $\mathrm{K}$, et al: IDO and regulatory $\mathrm{T}$ cell support are critical for cytotoxic T lymphocyte-associated Ag-4 Ig-mediated long-term solid organ allograft survival. J Immunol 188: 37-46, 2012.

24. Lin H, Bolling SF, Linsley PS, Wei RQ, Gordon D, Thompson CB and Turka LA: Long-term acceptance of major histocompatibility complex mismatched cardiac allografts induced by CTLA4Ig plus donor-specific transfusion. J Exp Med 178: 1801-1806, 1993.

25. Lenschow DJ, Zeng Y, Thistlethwaite JR, Montag A, Brady W, Gibson MG, Linsley PS and Bluestone JA: Long-term survival of xenogeneic pancreatic islet grafts induced by CTLA4Ig. Science 257: 789-792, 1992.

26. Orabona C, Puccetti P, Vacca C, Bicciato S, Luchini A, Fallarino F, Bianchi R, Velardi E, Perruccio K, Velardi A, et al: Toward the identification of a tolerogenic signature in IDO-competent dendritic cells. Blood 107: 2846-2854, 2006.

27. López AS, Alegre E, Díaz A, Mugueta C and González A: Bimodal effect of nitric oxide in the enzymatic activity of indoleamine 2,3-dioxygenase in human monocytic cells. Immunol Lett 106: 163-171, 2006.

28. Wiesinger $\mathrm{H}$ : Arginine metabolism and the synthesis of nitric oxide in the nervous system. Prog Neurobiol 64: 365-391, 2001.

29. Weitzberg E and Lundberg JO: Nonenzymatic nitric oxide production in humans. Nitric Oxide 2: 1-7, 1998.

30. Guan Y, Myron Y, Raja SN and Tao YX: Genetic knockout and pharmacologic inhibition of neuronal nitric oxide synthase attenuate nerve injury-induced mechanical hypersensitivity in mice. Mol Pain 3: 29, 2007.

31. Shaul PW, North AJ, Brannon TS, Ujiie K, Wells LB, Nisen PA, Lowenstein CJ, Snyder SH and Star RA: Prolonged in vivo hypoxia enhances nitric oxide synthase type I and type III gene expression in adult rat lung. Am J Respir Cell Mol Biol 13: 167-174, 1995.

32. Drobyski WR, Keever CA, Hanson GA, Mcauliffe T and Griffith OW: Inhibition of nitric oxide production is associated with enhanced weight loss, decreased survival, and impaired alloengraftment in mice undergoing graft-versus-host disease after bone marrow transplantation. Blood 84: 2363-2373, 1994.

33. Billiau AD, Fevery S, Rutgeerts O, Landuyt W and Waer M: Transient expansion of $\mathrm{Macl}^{+} \mathrm{Ly} 6-\mathrm{G}^{+} \mathrm{Ly} 6-\mathrm{C}^{+}$early myeloid cells with suppressor activity in spleens of murine radiation marrow chimeras: Possible implications for the graft-versus-host and graft-versus-leukemia reactivity of donor lymphocyte infusions. Blood 102: 740-748, 2003. 
34. Thomas SR, Mohr D and Stocker R: Nitric oxide inhibits indoleamine 2,3-dioxygenase activity in interferon-gamma primed mononuclear phagocytes. J Biol Chem 269: 14457-14464, 1994.

35. Alberati-Giani D, Malherbe P, Ricciardi-Castagnoli P, Köhler C, Denis-Donini $S$ and Cesura AM: Differential regulation of indoleamine 2,3-dioxygenase expression by nitric oxide and inflammatory mediators in IFN-gamma-activated murine macrophages and microglial cells. J Immunol 159: 419-426, 1997.

36. Roshick C, Wood H, Caldwell HD and McClarty G: Comparison of gamma interferon-mediated antichlamydial defense mechanisms in human and mouse cells. Infect Immun 74: 225-238, 2006

37. Hucke C, Mackenzie CR, Adjogble KD, Takikawa O and Däubener W: Nitric oxide-mediated regulation of gamma interferon-induced bacteriostasis: Inhibition and degradation of human indoleamine 2,3-dioxygenase. Infect Immun 72 : 2723-2730, 2004.

38. Ischiropoulos $\mathrm{H}$ : Biological selectivity and functional aspects of protein tyrosine nitration. Biochem Biophys Res Commun 305: 776-783, 2003

39. Hess DT, Matsumoto A, Kim SO, Marshall HE and Stamler JS: Protein S-nitrosylation: Purview and parameters. Nat Rev Mol Cell Biol 6: 150-166, 2005.
40. Sekkaï D, Guittet O, Lemaire G, Tenu JP and Lepoivre M: Inhibition of nitric oxide synthase expression and activity in macrophages by 3-hydroxyanthranilic acid, a tryptophan metabolite. Arch Biochem Biophys 340: 117-123, 1997.

41. Chiarugi A, Rovida E, Dello Sbarba P and Moroni F: Tryptophan availability selectively limits NO-synthase induction in macrophages. J Leukoc Biol 73: 172-177, 2003.

42. Oh GS, Pae HO, Choi BM, Chae SC, Lee HS, Ryu DG and Chung HT: 3-Hydroxyanthranilic acid, one of metabolites of tryptophan via indoleamine 2,3-dioxygenase pathway, suppresses inducible nitric oxide synthase expression by enhancing heme oxygenase-1 expression. Biochem Biophys Res Commun 320: 1156-1162, 2004

43. Fujigaki S, Saito K, Takemura M, Maekawa N, Yamada Y, Wada $\mathrm{H}$ and Seishima M: L-tryptophan-L-kynurenine pathway metabolism accelerated by Toxoplasma gondii infection is abolished in gamma interferon-gene-deficient mice: Cross-regulation between inducible nitric oxide synthase and indoleamine-2,3-dioxygenase. Infect Immun 70: 779-786, 2002.

44. Bronte V and Zanovello P: Regulation of immune responses by L-arginine metabolism. Nat Rev Immunol 5: 641-654, 2005. 